\title{
AS DIFICULDADES QUE PERMEIAM A APROPRIAÇÃO DA LINGUAGEM DOS ALUNOS EM DIFERENTES CONTEXTOS
}

\section{THE DIFFICULTIES THAT PERMIT THE APPROPRIATION OF THE LANGUAGE OF STUDENTS IN DIFFERENT CONTEXTS}

Maria José Bestete de Miranda ${ }^{1}$

\section{RESUMO}

Esta pesquisa tem como objetivo principal verificar a percepção de um grupo de mestrandos no que diz respeito as dificuldades que os alunos encontram na apropriação da linguagem em contextos formais e informais. Neste sentido, deve-se levar em consideração os modo(s) como os estudantes pertencentes a comunidades sociais, culturais e, consequentemente, linguísticas tradicionais, e que frequentam contextos escolares externos a elas, adequam suas produções textuais aos diversos contextos enunciativos, tendo em vista a necessidade de utilização da variedade culta da língua, bem como percebem sua variedade linguística, ou seja, quais valores atribuem a elas. Traz como referencial teórico a perspectiva bakhtiniana de linguagem $(1992,2003,2013)$, os referenciais de Fávero et al. (1999), Marcuschi (2001) dentre outros teóricos que realizaram estudos sobre a oralidade, escrita e gêneros textuais. Trata-se de uma pesquisa qualitativa, que traz a pesquisa participante. O público-alvo são mestrandos do Programa de Pós-graduação em Ensino, Educação Básica e formação de Professores da Universidade Federal do Espírito Santo.

Palavras-chave: Produções textuais orais e escritos. Oralidade. Comunidade quilombola. Variedades linguísticas.

\footnotetext{
${ }^{1}$ Mestranda em Ciências da Educação pela FICS - Facultad Interamericana de Ciências Sociales, formada em Licenciatura Plena em Pedagogia pela Faculdade de Filosofia, Ciências e letras de Alegre. Licenciada em Artes Visuais pela Universidade Metropolitana de Santos. mariajosebestete@yahoo.com.br
} 


\section{ABSTRACT}

This research has as main objective to verify the perception of a group of masters students regarding the difficulties that the students find in the appropriation of the language in formal and informal contexts. In this sense, it is necessary to take into account the ways (s) as the students belonging to social, cultural and, consequently, traditional linguistic communities, who attend school contexts external to them, adapt their textual productions to the various enunciative contexts, in view of the need to use the cultured variety of the language, as well as perceive their linguistic variety, ie what values they attribute to them. It brings as theoretical reference the Bakhtinian language perspective (1992, 2003, 2013), the references of Fávero et al. (1999), Marcuschi (2001) among other theorists who carried out studies on orality, writing and textual genres. It is a qualitative research that brings the participant research. The target audience are masters of the Post-Graduate Program in Teaching, Basic Education and Teacher Training at the Federal University of Espírito Santo.

Palavras-chave: Oral and written textual productions. Orality. Quilombola community. Linguistic varieties.

Mestranda em Ciências da Educação, formada em Licenciatura Plena em Pedagogia pela Faculdade de Filosofia, Ciências e Letras de Alegre. Licenciada em Artes Visuais pela Universidade Metropolitana de Santos, mariajosebestete@yahoo.com.br.

\section{INTRODUÇÃO}

De maneira geral, o ensino da língua/linguagem nas escolas é pautado na variedade culta da língua, por isso as aulas de Língua Portuguesa priorizam o 
ensino da norma-padrão. Conforme estabelecida pela Academia de Letras a ortografia oficial, deve obedecer a uma maneira única de escrever, que é imposta por decreto-lei governamental.

Bagno (2006, p. 22) afirma que apesar da padronização da língua causar uma impressão de ser mais rica, mais complexa, mais versátil que todas as demais variedades da língua faladas pelas pessoas do país, ela nada tem de melhor que essas variedades, ela só tem mais que as outras.

Desse modo a padronização difunde-se numa ideologia de homogeneidade linguística ou, enfatizando de outra forma, o mito da língua única. Porém, de acordo com Navarro (2007), professores e alunos devem estar conscientes de que há formas alternativas para se dizer a mesma coisa, as quais servem a propósitos comunicativos diferentes e são recebidas de maneira diferenciada pela sociedade, ou seja, falamos e/ou escrevemos de maneira diversa, atendendo a propósitos interacionais também diversos, os quais dependem do contexto enunciativo que se nos apresenta. Nesse sentido, este estudo tem como principal objetivo analisar a percepção de um grupo de mestrandos do Programa de Pós-graduação em Ensino, Educação Básica e formação de Professores da Universidade Federal do Espírito Santo.

Esta pesquisa justifica-se pela relevância dos estudos sobre a apropriação das linguagens oral e escrita, haja vista que se constituem como modalidades da língua, intrínsecas ao processo ensino-aprendizagem, cujos usos adequados encontram-se em estreita ligação com a questão de inclusão social. Entendendo por inclusão o processo de tornarem-se participantes do ambiente social total (a sociedade humana vista como um todo, incluindo todos os aspectos e dimensões da vida - econômica, cultural, política, religiosa e todas os demais, além da ambiental) todos aqueles que se encontram, por razões de qualquer ordem, excluídos deste.

Enfatizamos, outrossim, que considerar a abordagem da oralidade em sala de aula no que concerne, não somente, mas também, à reflexão e análise sobre a produção de textos escritos, bem como seu funcionamento, torna-se pertinente e interessante no que tange à adequação da linguagem aos seus contextos de uso. 
Nessa perspectiva, o presente trabalho assume significância na medida em que propõe aos docentes da Língua Portuguesa instrumentos/possibilidades didáticos que colaborem para o aperfeiçoamento da prática de produção textual em sala de aula, no que tange tanto à importância do reconhecimento da variedade linguística trazida pelos estudantes da comunidade quilombola (utilizada em sua comunidade), bem como quanto ao uso da variedade culta da língua (por alguns teóricos denominada norma-padrão), tendo em vista às adequações quanto ao contexto enunciativo, servindo, dessa forma, como suporte para o desenvolvimento dos alunos.

\section{VARIAÇÃO LINGUÍSTICA: ASPECTOS IMPORTANTES NO PROCESSO DE ENSINO - APRENDIZAGEM DA LÍNGUA PORTUGUESA}

A partir da década de 60 , à luz da sociolinguística, as teorias defensoras da homogeneidade da língua passaram a ser refutadas. Conforme Murad e Silva (2012), não existiria "erro" ou "desvio" da norma-padrão, e sim variedades de uma mesma língua, havendo uma lógica estrutural tanto na língua-padrão quanto na língua não padrão, sendo, pois, indispensável a análise e a discussão acerca das variedades linguísticas em sala de aula.

Nessa perspectiva, Labov (1969) advoga que o serviço mais útil que os linguistas podem oferecer é retirar a ilusão da 'deficiência verbal' e proporcionar a noção mais adequada das relações entre dialetos-padrão e não padrão.

Reconhecemos, dessa forma, a língua como dinâmica e heterogênea; sendo assim, ela se manifesta de forma diversificada de acordo com a situação comunicativa em que se encontra. Ao encontro do exposto, Bakhtin (2003, p. 262), explicita que "[...] cada enunciado particular é individual, mas cada campo de utilização da língua elabora seus tipos 'relativamente estáveis' de enunciados, os quais denominamos gêneros do discurso". Portanto, os gêneros discursivos revelam e refratam a utilização da língua em contextos 
diferenciados, os quais refletem também suportes diversos e novos usos da linguagem em virtude de sua dinamicidade.

Com essa perspectiva, entendemos que trabalhar em sala de aula com a diversidade de gêneros discursivos torna-se imprescindível, uma vez que, nessa direção, pode-se evidenciar com os estudantes a utilização de diferentes variedades linguísticas ao encontro de situações enunciativas singulares, que trazem interlocutores, temáticas e estruturas composicionais também diferenciadas.

Com relação ao ensino do oral na escola, segundo Castilho (1998, p. 13, apud FÁVERO et al., 1999, p. 12),

[...] não se acredita mais que a função da escola deve concentrar-se apenas no ensino da língua escrita, a pretexto de que o aluno já aprendeu a língua falada em casa. Ora, se essa disciplina se concentrasse mais na reflexão sobre a língua que falamos, deixando de lado a reprodução de esquemas classificatórios, logo se descobriria a importância da língua falada, mesmo para a aquisição da língua escrita.

Marcuschi (2001, p. 26) destaca que há várias tendências de tratamento da relação entre fala e escrita. Conscientizados dessas tendências, os professores de Língua Materna podem tratar a questão de uma forma "[...] mais frutífera, menos comprometida com o preconceito e desvalorização da oralidade de uma maneira geral".

Enfatizando a teoria saussuriana, Fávero (2005) ressalta que, historicamente, a escrita era considerada a verdadeira forma de linguagem, e a fala, por ser mais flexível, não constituía objeto de estudo. Só após 1960, a linguagem falada deixou de ser considerada uma mera verbalização. A língua como processo inacabado, resultado das construções do passado e do presente, e passou a ser incorporada às análises textuais. Sendo assim, "[...] a linguagem é, ao 
mesmo tempo produto da cultura, e é o principal instrumento para sua transmissão [...]". (SOARES, 2002, p. 16).

Mediante o explicitado, entendemos que mudanças linguísticas ocorrem tanto na escrita quanto na fala, daí seu aspecto dinâmico e heterogêneo, uma vez que se dá em sociedade. No que tange a esse aspecto, Bakhtin (1999, p. 112) enfatiza que "[...] a enunciação é o produto da interação de dois indivíduos socialmente organizados [...]" (BAKHTIN, 1999, p. 112). Nessa perspectiva, considerando a prática de produção textual como atividade social e discursiva. Os Parâmetros Curriculares de Ensino (PCNs, 1997, p. 21), declaram que:

A produção de discurso não acontece no vazio. Ao contrário, todo discurso se relaciona, de alguma forma, com os que já foram produzidos. Nesse sentido, os textos, como resultantes da atividade discursiva, estão em constante e contínua relação uns com os outros, ainda que, em sua linearidade, isso não se explicite.

Considerando, pois, a língua como atividade interativa, o texto é entendido como um evento comunicativo. Portanto, se a língua não é apenas uma forma e o texto apenas um artefato ou produto, a atenção e a análise dos processos de compreensão recaem nas atividades, nas habilidades e nos modos de produção de sentido, bem como na organização e condução das informações. (MARCUSCHI, 2008, p. 242).

Nesse sentido, as abordagens, em concomitância, da oralidade e escrita tornam-se extremamente significantes no processo de ensino aprendizagem da língua, no qual devem ser consideradas as orientações teóricas e as metodologias que visam facilitar a adequação das produções textuais a diferentes contextos.

Godinho (2006) advoga que se devem buscar formas/metodologias de abordagem da língua que permitam que o aluno se aproprie de diferentes dimensões da língua e possa operá-la em contextos significativos variáveis de comunicação. Dessa forma, o ensino aprendizagem da linguagem torna-se primordialmente relevante não só para os alunos, mas também para os 
professores, tendo em vista a produção de sentidos na instauração de processos interlocutivos significativos.

\section{A ORIGEM DA COMUNIDADE QUILOMBOLA MONTE ALEGRE}

A comunidade quilombola Monte Alegre, localizada na zona rural do município de Cachoeiro de Itapemirim- ES, de acordo com Ventura (2016) esta comunidade sempre foi apresentada ao público em situações de constrangimento, evidenciando os problemas sociais, contudo não thes eram apresentadas alternativas que solucionassem tal problemática.

O processo de formação da comunidade Monte Alegre se iniciou no contexto das relações entre os escravos e os senhores. Conforme a pesquisa realizada por Oliveira entre 2005 e 2006 e por meio da leitura do livro simplesmente Monte Alegre, ele afirma que no período da final da escravidão, alguns personagens foram constituindo famílias.

Ventura(2016) afirma que a comunidade quilombola Monte Alegre teve origem através do ajuntamento de negros abolidos das Fazendas São João da Mata, Santa Rosa, Barra do Mutum e Monte Alegre.

Conforme Oliveira(2016), "no final do século XIX, as famílias estavam entre si relacionadas entre si por alianças matrimoniais e laço de parentesco e constituíam famílias negras nos arredores de Monte Alegre".

A história oral da região relata que, após o fim da escravidão alguns desses ancestrais teriam recebido doações de terras, enquanto outros teriam obtido terras por compra ou ocupação.

Oliveira(2016) informa ainda que a violência sofrida pelos escravos não os tornou seres passivos, como pretendiam os escravocratas, pois, para seus descendentes, narrar seus feitos e saberes é honrá-los como heróis e protagonistas da história desta comunidade. 
Nessa perspectiva, esses ancestrais acionaram saberes acerca do mundo social africano que somaram àqueles que foram criados no Brasil.

Oliveira (2016) fomenta que "a criatividade destas famílias jamais pôde ser aprisionada e suas memórias têm atravessado tempos, gerações e espaços, tornando-se um demarcador de seu território".

\section{RESULTADO E DISCUSSÃO}

Para realização desta pesquisa houve a participação de um grupo de mestrandos do Programa de Pós-graduação em Ensino, Educação Básica e formação de Professores da Universidade Federal do Espírito Santo. Estes responderam um questionário online que como duas perguntas. Dessa forma, 0 grupo pesquisado foi constituído por uma população de 10 sujeitos que atuam em diversas áreas do conhecimento, sendo no campo da psicologia, pedagogia, matemática, ciências biológicas, química e letras, e por este motivo se deu a escolha deste grupo.

Nessa perspectiva as respostas obtidas constituíram o banco de dados, que foi tratado e analisado no programa RStudio com o suplemento RQDA, software de análise estatística para inferências qualitativas.

O banco de dados contendo todas as respostas foi formatado único texto, em seguida foi realizada a leitura flutuante (BARDIN,1977) e a partir dele realizada a divisão de categorias e subcategorias. Cada categoria foi pensada tomando por base as questões:

Quais são as principais dificuldades encontradas pelos alunos na apropriação da linguagem escrita em contextos formais e informais?

\section{QUADRO 1}




\begin{tabular}{|l|l|}
\hline \multirow{4}{*}{ Dificuldades dos alunos } & Desmotivação \\
\cline { 2 - 2 } & \\
\hline \multirow{4}{*}{ Percepção dos professores } & Pábitos \\
\hline \multirow{4}{*}{ Prática docente } & Problemas familiares \\
\cline { 2 - 2 } & Desestímulo \\
\cline { 2 - 2 } & Dificuldades na escrita \\
\cline { 2 - 2 } & Desinteresse \\
\hline & Formação Inicial e Continuada \\
\cline { 2 - 2 } & Didática \\
\cline { 2 - 2 } & Metodologia \\
\cline { 2 - 2 } & Reflexão \\
\hline
\end{tabular}

Cada categoria foi elaborada com objetivo de responder à questão principal sobre a dificuldade dos alunos no que diz respeito a apropriação da linguagem. Nessa perspectiva, foram descritas:

As dificuldades dos alunos provocam questionamentos e reflexões. Nesse sentido esperam-se que os professores busquem respostas e desenvolvam ações que visam contribuir para o desenvolvimento do educando no processo de ensino-aprendizagem de Língua Portuguesa.

Após a descrição das categorias, novas foram criadas e percebendo a relação com as já existentes foram organizadas como subcategorias, conforme apresentado na Tabela 1. A seguir serão apresentadas as considerações dos entrevistados frente à questão investigativa que concerne esta pesquisa.

\section{TABELA 1}

Quais são as principais dificuldades encontradas pelos alunos na apropriação da linguagem escrita em contextos formais e informais?

\section{Sujeito A}


(...) dificuldade de interpretação dos alunos, derivada da falta de concentração.

\section{Sujeito B}

A falta de interesse é um fator que contribui para a evolução das dificuldades

\section{Sujeito C}

(...) a pouca formação docente focada na alfabetização.

\section{Sujeito D}

O fato de não dominarem a ortografia.

Sujeito E

Pouca leitura de livros, e de outros materiais que propicie um enriquecimento no vocabulário e na escrita.

\section{Sujeito F}

Essa dificuldade poderia justificar-se pelo fato da cultura vivenciada não estar diretamente relacionada à linguagem escrita padronizada como a correta para situações formais.

\section{Sujeito G}

(...) se o estudante possui vocabulário restrito, logo sua escrita também será restrita.

\section{Sujeito}

No cotidiano seria mais favorável aprender os termos a serem usados em cada ocasião sabendo sempre com quem está dialogando.

\section{Sujeito I}

Encontramos muitos docentes despreparados com sérias deficiências em sua formação inicial e pouco expostos a momentos de formação continuada, despreparados para refletir e implementar estratégias didáticas mais dinamizadoras para o ensino da língua portuguesa.

De acordo com os apontamentos dos entrevistados com relação a dificuldade de apropriação de linguagem, pode-se afirmar que a falta de concentração interfere na interpretação do aluno e o modo como ele irá operar o sistema linguístico. Outro fator que deve ser levado em consideração é o contexto onde 
o educando está inserido, assim como a falta de estímulo da família com relação ao desenvolvimento do educando.

A dificuldade na escrita por não dominarem devidamente a ortografia e a falta de leitura, contribuem fortemente para que o aluno tenha um vocabulário restrito, dificultando a aplicabilidade da linguagem em diferentes contextos.

Um dos entrevistados salientou que há pouca formação na área de alfabetização, bem como na formação continuada, tornando-os despreparados no sentido de inovar suas aulas, aplicando estratégias dinâmicas no ensino da Língua Portuguesa.

Logo, a língua, enquanto produto desta história e enquanto condição de produção da história presente vem marcada pelos seus usos e pelos espaços sociais destes usos. Sendo assim, a língua nunca pode ser estudada ou ensinada como produto acabado, pronto, fechado em si mesmo [...] (GERALDI, 2006, p. 28).

Nesse sentido produziu - se a árvore de similitude máxima dos termos RS, procurando evidenciar as principais dificuldades encontradas pelos alunos com relação a apropriação da linguagem em diferentes contextos, sendo eles formais ou informais. Para tanto, empregou-se o IRAMUTEQ (Interface do R pour les Analyses Multidimennsionelles de Textes at de Questionnaires, RATINAUD; DEJEAN, 2008).

Portanto, para a análise desta pesquisa, selecionaram-se os termos de maior proeminência, ou seja, aqueles utilizados com maior frequência; são em suma, ocorre um frequência de corte que tem o intuito de diminuir a dispersão dos termos, possibilitando a convergência da análise, proporcionando um resultado conciso quanto à composição do elementos estruturais RS. 


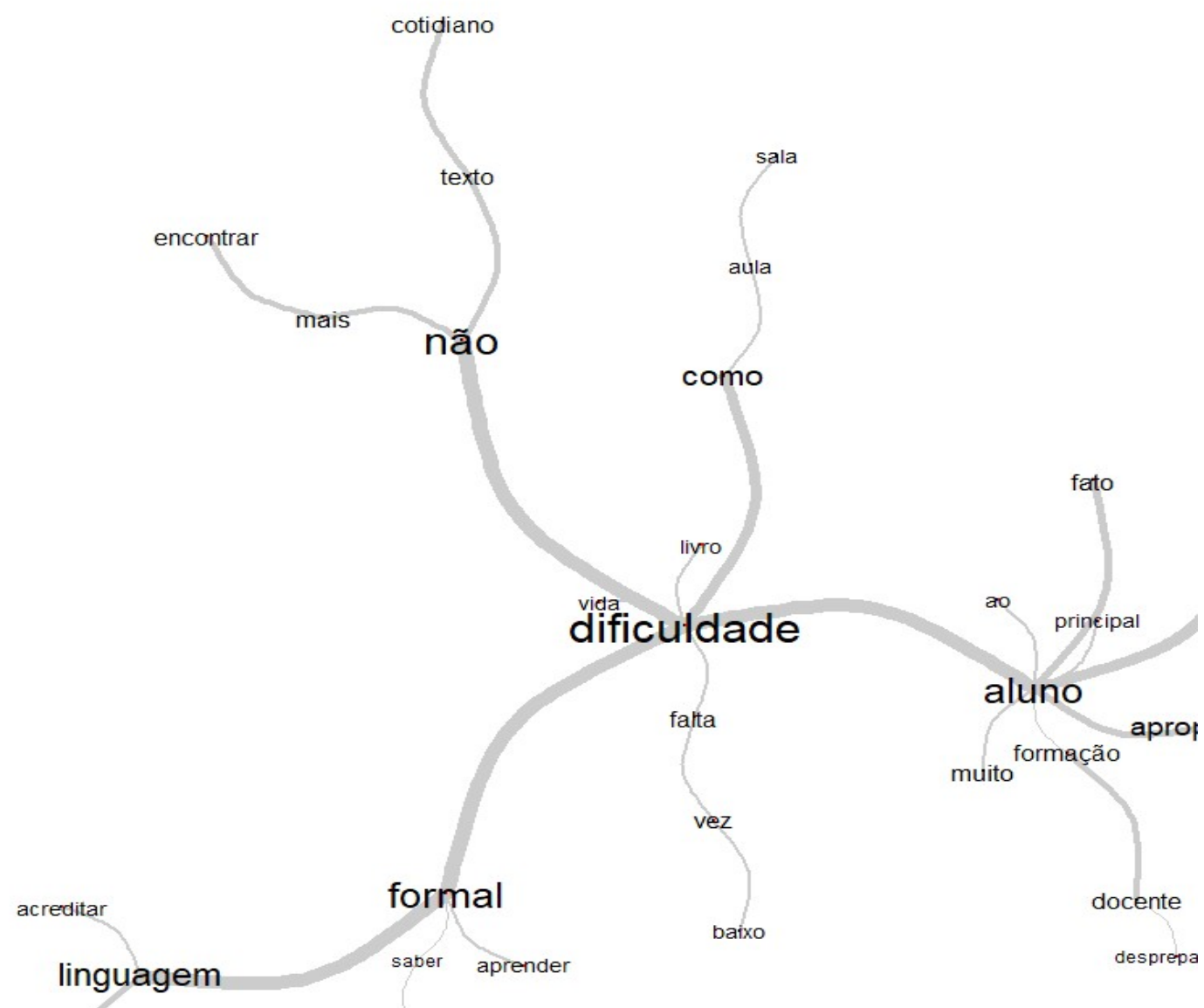

Figura 01- Árvore máxima de similitude fornecida pelo IRAMUTEQ para termos representativos: Dificuldades dos alunos com relação a apropriação da linguagem.

Analisando a figura 01, referente a dificuldade de apropriação da linguagem, é possível identificar os termos que os termos de maior conexidade são dificuldade, não, formal e linguagem que estão relacionados aos termos com menor frequência.

Fazendo a leitura atenta da tabela 02, pode-se constatar que os termos com maior frequência estão relacionados ao termo central.

Tabela 02- Termos e frequência obtidos pela análise máxima de similitude sobre a dificuldade dos alunos com reação a apropriação da linguagem. 
Tabela 2

\begin{tabular}{|l|l|l|}
\hline TERMOS & FREQUÊNCIA & \\
\hline Dificuldade & 16 & \\
\hline Não & 15 & \\
\hline Formal & 12 & \\
\hline Fontexto & 8 & \\
\hline Escrita & 8 & \\
\hline
\end{tabular}

Logo, com a apresentação dos dados da pesquisa é possível compreender quais são os termos que melhor representam a percepção do grupo de alunos do mestrando que contribuíram para realização deste estudo. 
As evidências apresentadas na análise deste estudo reforçam a tese de que a dificuldade de apropriação da linguagem pelos alunos consiste na falta de leitura, desinteresse, que muitas vezes são ocasionados pelo contexto onde o mesmo está inserido, levando e consideração que este nem sempre recebe o estímulo necessário para o seu desenvolvimento educacional.

Frente aos apontamentos instaurados nesta pesquisa, sugere-se a formação continuada com o objetivo não apenas de conhecimento, mas no intuito de causar uma reflexão sobre as práticas e metodologias utilizadas no processo de ensino-aprendizagem da língua portuguesa.

\section{REFERÊNCIAS}

BAGNO, C. A Língua de Eulália: Novela Sociolinguística. São Paulo: Contexto, 2006.

BAKHTIN, M. Marxismo e Filosofia da Linguagem. 9a ed. São Paulo: Hucitec, 1999.

. Estética da criação verbal. $4^{a}$ ed. São Paulo: Martins Fontes, 2003.

BARDIN, L. Análise conteúdo. Lisboa: Edições 70, 1977, 255 p.

BRASIL. Ministério da Educação e do Desporto. Secretaria de Educação Fundamental. Parâmetros Curriculares Nacionais: Língua Portuguesa. Brasília, 1997.

FÁVERO, L. L.; ANDRADE, M. L. da C. V. de O.; AQUINO, Z. G. O. de. Oralidade e escrita: perspectivas para o ensino de língua materna. São Paulo: Cortez, 1999.

- Oralidade e escrita: perspectiva para o ensino de língua materna. $5^{a}$ ed. São Paulo: Cortez, 2005.

GERALDI, J. W. O texto na sala de aula. $4^{a}$ ed. São Paulo: Ática, 2006. 
NAVARRO, A. M.M. Contribuição Da Sociolinguística Para o Tratamento Didático Da Variação Linguística $\mathrm{Na}$ Escola. Disponível em: < http://www.diaadiaeducacao.pr.gov.br/portals/pde/arquivos/611-4.pdf $>$. Acesso em: 12 de dezembro de 2017.

MARCUSCHI, L. A. Produção Textual, Análise de Gêneros e Compreensão. São Paulo: Parábola Editorial, 2008.

MARCUSCHI, L. A. Da Fala Para a Escrita: Atividades de Retextualização. São Paulo: Editora Cortez, 2001.

MURAD, C. R. R. O., SILVA, M. da. Variação Linguística e Ensino de Língua Portuguesa: O Professor Da Educação Infantil Como Promotor Do Diálogo Entre Ciência e Sala de Aula. In: SIMPÓSIO INTERNACIONAL DE ENSINO DE LÍNGUA PORTUGESA SIELP. 2012. Anais Do SIELP. Uberlândia: EDUFU, 2012. p. 1-12.

OLIVEIRA, O.M. e O. Território Quilombola de Monte Alegre História Cultura, Meio ambiente e Direito Étnico. 2006. 362 folhas. Relatório Técnico de Identificação da Comunidade Remanescente de Quilombos de Monte Alegre, Universidade federal do Espírito Santo-UFES, INCRA, Vitória, 2006.

SOARES, M. Linguagem e Escola: Uma Perspectiva Social. 17a. Ed. São Paulo: Ática, 2002.

VENTURA, L. Simplesmente Monte Alegre. Cachoeiro de Itapemirim. Editora: Cachoeiro Cult. 2016 